Journal of Computer Science 2 (1): 13-18, 2006

ISSN 1549-3636

(c) 2006 Science Publications

\title{
WiFi Technology: Future Market Challenges and Opportunities
}

\author{
Adel Ismail Al-Alawi \\ Department of Management Information Systems, College of Information Technology \\ University of Bahrain, P.O. Box 32038, Kingdom of Bahrain
}

\begin{abstract}
Computer networks have played a major role in expanding the operational boundaries in organizations today. Until now traditional methods of networking, which involves computers, wired directly to a hub or switch are the norm. Recent advances in networking technology have made it possible for devices to communicate using various light and wave emitting technologies. WiFi is a perfect example of one of these emerging technologies, which has enabled computers to communicate with each other without the use of traditional cables. The implementation of WiFi with respect to future market opportunities in the Kingdom of Bahrain will be discussed in this study. Finally, an analysis of various demographics will be outlined with particular concentration on the acceptance of WiFi by society in the Kingdom of Bahrain. Some concerns along with recommendations, which need to be taken into account when using WiFi are also outlined.
\end{abstract}

Key words: Bahrain, WiFi, factors, security, speed

\section{INTRODUCTION}

The Internet plays a major role in today's communications, especially when its efficient and cost effective manner is considered. Unlike, other communication tools, Internet has been decentralized in such a way that any user can share, retrieve, sell or exchange goods and services with any other Internet user within seconds.

Earlier in the 1970s to the late 1980s, the Internet was owned and funded by the United States government and thus was mainly used for government communication and research activities, which was highly restricted to academic and military purposes. It was administrated by the National Science Foundation (NSF). By 1995, however the NSF stopped the administration of the Internet. The Internet was publicized and commercial use was permitted ${ }^{[1-3]}$.

Bahrain Telecommunication Company (BATELCO) was one of the pioneers to adopt the Internet technology. This fact has strengthened BATELCO's position as a leading communication provider in the region.

Today the Internet has touched our life in a significant manner. It became part of our daily routine due to the huge benefits we gain. Most companies went online and used the Internet to apply e-commerce, which includes advertising, selling, buying, distributing products and providing customer services. In addition, companies use the Internet in business-to-business and business to consumer transactions. Individuals also use the Internet for communication, entertainment, sharing information, buying and selling goods and services.
Over the last couple of years, Wireless Fidelity or "WiFi" has quickly grown to become the dominant wireless LAN standard. Because it operates in unlicensed frequency bands, any one can set up a WiFi network and cover an area of typically 100-500 feet with high speed wireless access to a LAN and hence to the Internet. Unlike other wireless technologies like GSM or CDMA, WiFi has also become a universal standard. As a result, WiFi components are now on a rapid cost reduction curve as volumes increase. And it is widely distributed and used in many different parts of the world ${ }^{[4]}$.

$\mathrm{WiFi}$ is the term used to describe a class of certified wireless networking products conforming to an industry standard designated by the Institute of Electrical and Electronics Engineers (IEEE) as "802.11b", it is a new technology that is preferred for wireless local area networking in both business and home environments.

Wireless local area networks enable network users with laptops or devices equipped with wireless network interface cards to remain constantly interconnected while roaming within the range of a base station. Fixed access points can also be interconnected with wide area networks, such as the Internet or intra-corporate local area networks. WiFi is being deployed in public places to create what is called hotspots, where WiFi capable users can obtain broadband Internet access ${ }^{[5]}$.

WiFi could be a major future market opportunity. But, in order to take advantage of it, several key challenges both business related and technical must be overcome. These challenges and solutions approaches are discussed in this study, with respect to

Corresponding Author: Dr. Adel Ismail Al-Alawi, Department of Management Information Systems, College of Information Technology, University of Bahrain, P.O. Box 32038, Kingdom of Bahrain, Mob: +973-36779000 
BATELCO $^{[6]}$ the dominant telecommunications company in Bahrain.

What is WiFi?: WiFi is the popular name for the wireless Ethernet $802.11 \mathrm{~b}$ standard for WLANs and it reefers to the technology surrounding the radio transmission of the Internet protocol data from an Internet connection wirelessly to a host computer. Most often the Internet connection is a higher speed one such as satellite, DSL or cable rather than slower dial-up connections. It is essentially a wireless connection between your computer and the Internet connection (E.g. DSL router or cable modem) in your house ${ }^{[4]}$.

'Wireless Fidelity' WiFi refers to an over-the-air connection with a wireless client and a base between two wireless clients ${ }^{[7]}$. WiFi, is freedom: it allows you to connect without wires to the Internet from your couch at home, a bed in a hotel room or a conference room at work. WiFi is a wireless technology like a cell phone. WiFi enables computers to send and receive data indoors and outdoor; anywhere within the range of a base station. The best thing of all, it is fast. In fact, it's several times faster than the fastest cable modem connection.

\section{The drivers and nature of today's WiFi:}

Many drivers had evolved over the years that made online banking a must. This is the time for planning a trial of local WiFi service, at a major shopping mall and a number of hotel lobbies, as an alternative to rolling out a 3G network. The plan is based on urban layout and social behavior. In short, the people like to 'cluster' in public places such as shopping malls, coffee houses and hotels - prime locations for WiFi ennoblement. As in Bahrain, BATELCO's Head of Corporate Affairs, explained:

"Bahrainis do not need the kind of on-the-move service that $3 \mathrm{G}$ is designed to offer. The Kingdom has minimal public transport because it has a 'car culture' so no demand exists there for 3G. I don't see a need for $3 \mathrm{G}$ in the home because people will want to use largerscreen PCs to access the 'net. It's too hot here to sit on the beach and surf the 'net - so that leaves the shopping malls, coffee shops and hotel lobbies, which we can enable with faster WiFi technology. In addition, Bahrain has a high proportion of youngsters' technology users who will be eager to use this kind of service and Bahrain, is a real winner here" ${ }^{[6]}$.

You will find as of now and the upcoming future, that more and more large businesses are using WiFi certified products. In stores throughout the mall, WiFi LAN technology is expanding its use with WiFi certified computers, employees can use for easy access in communicating with other employees online.

WiFi-industry growth: The President and CEO of CTIA has argued that wireless data is advancing at a particularly swift clip, as more companies introduce more features for consumers and business users alike.
From ring tones to picture phones, from text messaging to hi-speed wireless Web browsing, wireless data is making waves in both the consumer and business marketplaces. Total Service Revenues Rise Nearly 13\% - U.S. Carriers earned service revenues of $\$ 41.4$ Billion in the first six months of 2003, up from $\$ 36.7$ billion in the first six months of $2002^{[8]}$.

The future of WiFi: Another interesting aspect of WiFi maybe the question of what is the future of WiFi? Levkowet ${ }^{[9]}$ has argued that in today's vast growing world of telecommunications many new products; software and hardware tools are being developed. Computer engineers are working around the clock just to come up with new ideas that may be accomplished. Until now, with wireless networking the simplicity of placing a computerized device within an access point will allow people to connect to the cyber world. Consequently, the development process is continuing until a certain standard is reached. Even though there is a wide acceptance regarding $\mathrm{WiFi}$, people will still be concerned will things like security and cost.

Whenever, a new technology is being sold in the market several buyers thrive to purchase it regardless of its price. But, the problem arises when a certain defect might be seen within the product. That is why people are very demanding they do not want a flawless product to operate with and in situations like this, manufacturers will strive to produce a product that meets their needs. On the other hand, Lyman ${ }^{[10]}$ has emphasized on the concern of security and complexity of WiFi. In response to concerns over complexity and security, wireless industry experts promised new standards that should begin appearing in products throughout next year.

Advantages of WIFI: Another advantage of WiFi network is that the availability of WiFi products in the market has increased oven the last three years. Many companies strive to ensure that users get the most updated software and hardware equipment in order to allow them to access a WiFi network. Due to the wide availability of products in the market the issue of pricing plays a significant role here. Apparently market forces are a major determinant of the prices available on products today. Also, taking into account mobility is an advantageous aspect of a WiFi network. People will be able to move about the given hotspot without loosing the network connection of $\mathrm{WiFi}^{[11]}$.

Disadvantages of WIFI: Disadvantage or constraint is placement. When using a WiFi network the frequency specification used is $802.11 \mathrm{~b}$, which is the same frequency that many cellular phones, blue tooth, microwave ovens operate on. So it is in the hands of the $\mathrm{WiFi}$ users to choose an access point that is not close to the one of the devices mentioned, because an interruption will occur and this may cause a loss of 
signal or it may deteriorate the connection ${ }^{[12]}$. BATELCO is launching the service coinciding with the arrival of thousands of visitors to the country for the Gulf Air Bahrain Grand Prix and initial base station installations reflect the Formula One crowd. The airport, Costa Coffee shops in Seef and Adliya, Al A'ali Mall food-court and the Crown Plaza and Gulf Hotel lounges will be the first to offer BATELCO WiFi services. From April onwards, the service will be rolled out to additional locations all over the country ${ }^{[13]}$. WiFi is becoming popular in many homes and offices throughout Bahrain and by adding a broad range of publicly located base stations; BATELCO is tapping into a demonstrated need amongst customers.

\section{HYPOTHESIS AND METHODOLGY}

The research hypothesis: A hypothesis can be defined as a logical supposition, a reasonable guess or an educated conjecture. Furthermore, it can provide a tentative explanation for a phenomenon under investigation and it could involve a prediction that may or may not be borne out in the data. It should be noticed that hypothesis never proved or disproved, either supported or not supported by the data and over time as particular hypothesis are supported by a growing body of data, they evolve into theories.

Hypothesis: Low connection speed will no longer be an issue with WiFi as there is a more dedicated speed with WiFi.

The research methodology: Both face-to-face interviews and questionnaire were used. Face-to-face interviews encourage potential participant and gain their co-operation thus yielding the highest response rate in a survey research. They also allow the respondent to ask about any ambiguous questions and in the same time allow the researcher to seek follow up information. Interviews were conducted with selected representatives.

Based on the objectives and the hypothesis, the questions were set in the questionnaire in order to test them and ultimately to confirm or disconfirm the proposed hypothesis, i.e. the questionnaire will reflect the research hypothesis in a direct way as a method for testing it along with the objective.

The researcher chose a mixture of both qualitative and quantitative method techniques in order to conduct information about our research topic. We choose this approach to help us monitor and examine the arrival of this new wireless technology, which is called $\mathrm{WiFi}$ and to solve its optical and to examine if this technology will be beneficiary to open new investments in Bahrain and increase the success of old investments.

Fifty copies of the questionnaire were distributed to target the users that will use this technology and how can this increase the efficiency of their work.
The chi square test and correlations tests were used in order to test the research hypothesis. These statistical tests were conducted using the SPSS statistical software, which is specialized software that facilitates the analysis of any research findings.

The sources of data: In general, the sources of evidence used in this research are documents and direct questionnaire. The questionnaire audiences are residential end users, business men and women, hotel and coffee shop management as well as some BATELCO staff. The data has been collected from documents, search engines, books and BATELCO's official website.

\section{RESULTS AND DISCUSSION}

Analysis of customer perception: The majority of our samples were males representing $58.1 \%$.

Table 1: Respondents Learned about WiFi

\begin{tabular}{ll}
\hline Where Did you Hear about WIFI & Sample \\
\hline Internet & $48.4 \%$ \\
Friends & $7 \%$ \\
Newspaper \& Magazines & $7 \%$ \\
No Answer & $18.6 \%$ \\
Other Resources & $18.6 \%$ \\
\hline
\end{tabular}

Table 2: Usage of WiFi

\begin{tabular}{ll}
\hline Used WIFI & Sample \\
\hline Yes & $48.8 \%$ \\
No & $32.6 \%$ \\
No Answer & $18.6 \%$ \\
\hline
\end{tabular}

Table 3: Frequently use of WiFi

\begin{tabular}{ll}
\hline Frequently use of WIFI & Sample \\
\hline Daily & $11.6 \%$ \\
Weekly & $7 \%$ \\
Monthly & $7 \%$ \\
Occasionally & $23.3 \%$ \\
Others & $23.3 \%$ \\
Did not answer & $48.8 \%$ \\
\hline
\end{tabular}

Table 4: Reasonsp people use WiFi

\begin{tabular}{ll}
\hline Reasons People use WIFI & Sample \\
\hline Low Cost & $16.4 \%$ \\
Stable Connectivity & $7 \%$ \\
Higher Speed & $2.3 \%$ \\
More Convenient & $20.9 \%$ \\
Time Consuming & $2.3 \%$ \\
Others & $2.3 \%$ \\
Did Not Answer & $48.8 \%$ \\
\hline
\end{tabular}

Table 5: Disadvantages of WiFi

\begin{tabular}{ll}
\hline Disadvantage of WIFI & Sample \\
\hline Lack of Awareness & $46.5 \%$ \\
Security Issues & $20.9 \%$ \\
Resistance to Change & $11.6 \%$ \\
Service is not provided yet by ISP & $8.15 \%$ \\
Service is not convenient yet all Place & $8.15 \%$ \\
Others & $4.7 \%$ \\
\hline
\end{tabular}


Table 6: Scale of WiFi Factors

\begin{tabular}{|c|c|c|c|c|c|}
\hline WiFi Factors & $\begin{array}{l}\text { Strongly } \\
\text { agree }\end{array}$ & Agree & Neither & Disagree & $\begin{array}{l}\text { Strongly } \\
\text { Disagree }\end{array}$ \\
\hline $\begin{array}{l}\text { 1. Speed } \\
\mathrm{WiFi} \text { is faster as compared to traditional cable internet }\end{array}$ & $39.5 \%$ & $20.9 \%$ & $12.8 \%$ & $14 \%$ & $12.8 \%$ \\
\hline $\begin{array}{l}\text { 2. Cost } \\
\text { WiFi is cheaper as compared to traditional cable internet }\end{array}$ & $39.5 \%$ & $20.9 \%$ & $18.6 \%$ & $14 \%$ & $7 \%$ \\
\hline $\begin{array}{l}\text { 3. Stable Connectivity } \\
\text { WiFi provides a more stable connection than other } \\
\text { technologies. }\end{array}$ & $30.2 \%$ & $27.9 \%$ & $25.6 \%$ & $14.5 \%$ & $2.3 \%$ \\
\hline $\begin{array}{l}\text { 4. Convenient } \\
\text { WiFi is more convenient than other technologies }\end{array}$ & $34.9 \%$ & $44.2 \%$ & $11.6 \%$ & $9.3 \%$ & $0 \%$ \\
\hline $\begin{array}{l}\text { 5. Time Saving } \\
\text { WiFi saves users time }\end{array}$ & $39.5 \%$ & $32.5 \%$ & $18.6 \%$ & $4.7 \%$ & $4.7 \%$ \\
\hline $\begin{array}{l}\text { 6. Security } \\
\text { Security issues of WiFi acts as a barrier to adopting the } \\
\text { technology }\end{array}$ & $53.5 \%$ & $20.9 \%$ & $11.6 \%$ & $9.3 \%$ & $4.7 \%$ \\
\hline
\end{tabular}

Most of the respondents were between the age of 20 and 30 years of age. $58.1 \%$ of the respondents were employed and $74.4 \%$ of our samples were familiar with the wireless technology. About $81.4 \%$ of our sample heard about WIFI and most of them used it. We found out that $46.5 \%$ of the major reason running away from using WIFI is the lack of awareness.

When the respondents were asked from where did they hear about WiFi? Table 1 show that the majority 48.4\% learned about WiFi from the Internet.

As illustrated in Table 2 more than 50\% of respondents never used the WiFi or did not respond to this question.

When the respondents were asked how frequently they use the WiFi? From those who used the WiFi $23.3 \%$ used the service occasionally (Table 3 ).

When the respondents were asked what are the reasons that would people use WiFi over other Internet connections? As Table 4 illustrates that the majority $20.9 \%$ said that because it is more convenient.

When the respondents were asked in their opinion, what are the reasons that would push people away from using WiFi technology? As it is illustrated in Table 5, the majority of the respondents agreed that the major disadvantage of WiFi is the lack of awareness.

In the Table 6 the questions are divided into six Factors concerning speed, cost, stable connectivity, convince, time saving and security issues associated to WiFi. Most of the respondents strongly agree that the security has the highest rate of important, while Speed, Cost and Time Saving are give the same rate 39.5\%, follows by Convenient than Stable Connectivity 30.2\%.

The majority of respondents ranked Security number 1, Speed number 2, Cost number 3, Time Saving number 4, Convenient number 5 and Stable connectivity number 6 when they were asked to rank the factors. Table 7 illustrates the Factors ranking according to the respondent's level of agreement.

The majority of respondents' reaction to the set of questions that deal with speed, cost effectiveness, fast

\begin{tabular}{ll} 
Table 7: & Factors Ranking \\
\hline Rank & Factor \\
\hline 1 & Security \\
2 & Speed \\
3 & Cost \\
4 & Time Saving \\
5 & Convenient \\
6 & Stable connectivity \\
\hline
\end{tabular}

Table 8: Level of agreement on world word usage of WiFi

\begin{tabular}{ll}
\hline WiFi used Worldwide & Sample \\
\hline Strongly agree & $23.3 \%$ \\
Agree & $60.4 \%$ \\
Neither & $4.7 \%$ \\
Disagree & 11.65 \\
Strongly Disagree & $0 \%$ \\
\hline
\end{tabular}

Table 9: $\quad$ Lack of Awareness

\begin{tabular}{ll}
\hline WIFI Lack of Awareness & Sample \\
\hline Strongly agree & $48.8 \%$ \\
Agree & $44.2 \%$ \\
Neither & $4.7 \%$ \\
Disagree & $0 \%$ \\
Strongly Disagree & $2.3 \%$ \\
\hline
\end{tabular}

Table 10: Popularity of WiFi in the near future

\begin{tabular}{ll}
\hline WIFI Future & Sample \\
\hline Strongly agree & $46.5 \%$ \\
Agree & $41.5 \%$ \\
Neither & $4.7 \%$ \\
Disagree & $4.7 \%$ \\
Strongly Disagree & $2.3 \%$ \\
\hline
\end{tabular}

connection, speeds convenience and security issues about WiFi tend to strongly agree to agree (Table 6). In addition $60.4 \%$ (Table 8 ) of them agreed that WiFi technology is world wide used and $48.4 \%$ strongly agreed (Table 9) the WiFi technology faces lack of user's awareness. Therefore, our samples of respondents seem to be familiar with WiFi and use it depending on the availability of the service in the specific areas "hotspots" that the ISP located.

Finally, Table 10 illustrates that popularity the WiFi will gain in the near future. The majority $88 \%$ of the respondents agree to strongly agree that the $\mathrm{WiFi}$ 
Table 11: The result of hotel questionnaire

\begin{tabular}{|c|c|c|c|c|c|c|c|c|c|}
\hline \multirow[t]{2}{*}{ Questions } & \multicolumn{9}{|l|}{ Name of hotels } \\
\hline & Sheraton & Movenpick & Novotel & Gulf hotel & Crowne plaza & Diplomat & Ritz Carlton & Regency & Helton \\
\hline $\begin{array}{l}\text { Do they } \\
\text { have WiFi? }\end{array}$ & $\mathrm{N}$ & $\mathrm{N}$ & $\mathrm{N}$ & $\mathrm{N}$ & $\mathrm{N}$ & $\mathrm{N}$ & $\mathrm{N}$ & $\mathrm{N}$ & $\mathrm{N}$ \\
\hline $\begin{array}{l}\text { Intereste in } \\
\text { Batelco Wifi? }\end{array}$ & $\mathrm{N}$ & $\mathrm{N}$ & $\mathrm{Y}$ & $\mathrm{Y}$ & $\mathrm{Y}$ & $\mathrm{Y}$ & $\mathrm{Y}$ & $\mathrm{Y}$ & $\begin{array}{l}\text { No } \\
\text { Answer }\end{array}$ \\
\hline Had a demo? & $\begin{array}{l}\text { No } \\
\text { Answer }\end{array}$ & $\mathrm{N}$ & $\mathrm{Y}$ & $\mathrm{N}$ & $\mathrm{Y}$ & $\mathrm{Y}$ & $\mathrm{Y}$ & $\mathrm{N}$ & $\begin{array}{l}\text { No } \\
\text { Answer }\end{array}$ \\
\hline $\begin{array}{l}\text { Received } \\
\text { quotation? }\end{array}$ & $\mathrm{y}$ & $\mathrm{y}$ & $\mathrm{y}$ & $\mathrm{y}$ & $\begin{array}{l}\text { No } \\
\text { Answer }\end{array}$ & $\begin{array}{l}\text { No } \\
\text { Answer }\end{array}$ & $\mathrm{Y}$ & $\mathrm{N}$ & Y \\
\hline $\begin{array}{l}\text { Interested in } \\
\text { a presentation? }\end{array}$ & $\mathrm{Y}$ & $\mathrm{N}$ & $\mathrm{Y}$ & $\mathrm{Y}$ & Y & $\begin{array}{l}\text { No } \\
\text { Answer }\end{array}$ & $\mathrm{Y}$ & $\mathrm{Y}$ & $\begin{array}{l}\text { No } \\
\text { Answer }\end{array}$ \\
\hline $\begin{array}{l}\text { Type of } \\
\text { Internet used? }\end{array}$ & $\begin{array}{l}\text { ADSL/ } \\
900400\end{array}$ & ADSL & 900400 & $\begin{array}{l}\text { ADSL/ } \\
900400\end{array}$ & 900400 & ADSL & $\begin{array}{l}\text { ADSL/ } \\
900400\end{array}$ & $\begin{array}{l}\text { ADSL/ } \\
900400\end{array}$ & $\begin{array}{l}\text { No } \\
\text { Answer }\end{array}$ \\
\hline $\begin{array}{l}\text { Have internet } \\
\text { billing system? }\end{array}$ & $\mathrm{N}$ & Y & $\mathrm{N}$ & $\mathrm{N}$ & $\mathrm{N}$ & Y & $\mathrm{N}$ & $\mathrm{N}$ & $\begin{array}{l}\text { No } \\
\text { Answer }\end{array}$ \\
\hline $\begin{array}{l}\text { Hotel billing } \\
\text { System }\end{array}$ & Fedelio & Fedelio & Fedelio & $\begin{array}{l}\text { Land } \\
\text { Mark }\end{array}$ & Fedelio & Fedelio & Fedelio & Fedelio & Fedelio \\
\hline $\begin{array}{l}\text { Wiring } \\
\text { structure }\end{array}$ & $\begin{array}{l}4 \text { wire } \\
\text { (TP) }\end{array}$ & $\begin{array}{l}\text { CAT } \\
5 / 6\end{array}$ & CAT5 & CAT5 & CAT5 & CAT6 & $\begin{array}{l}4 \text { wire } \\
(\mathrm{TP})\end{array}$ & CAT5 & $\begin{array}{l}\text { No } \\
\text { Answer }\end{array}$ \\
\hline
\end{tabular}

will play a very important function in our daily life in the near future.

Analysis of the hotel questionnaires: Table 11 shows that at the time of the survey all 9 hotels that were involved in the questionnaire don't have WiFi Technology, they were interested in $\mathrm{WiFi}$ provider which is BATELCO and most of them had a demo version of WiFi. Most of them were happy and asked for a seminar or workshop that explains $\mathrm{WiFi}$ in depth details, because they have an Internet billing system and Hotel billing system, so it will be good opportunity for those systems to be organized.

Table 11 shows the result of the simple questionnaire that was distributed among the five-star hotels in Bahrain, it's a simple questionnaire that examine their ability to be informed about $\mathrm{WiFi}$ technology in depth, in addition of the Internet type they use ,and their wiring system existed there.

Based on the findings, there are not any hotel has WiFi technology, but four of them have a demo version $(44.4 \%)$.however, five of the hotels are interested in $\mathrm{WiFi}(55.6 \%)$ and six of them received a WiFi's quotation from different suppliers $(66.7 \%)$, same of them were interested in a presentation to improve their awareness about WiFi.

According to the type of the Internet they used, we figure out that, six of them used Speednet (66.7\%), while the other used 900400(33.3\%). In addition, just two of them have an Internet Billing System (22.2\%), all of them used a Hotel Billing System, eight of hotels used fedelio System, while the remain used a Landmark System (11.1\%). Finally, six of the hotels used Cat5 $(66.7 \%)$ and the rest used Four-Wire (33.3\%).

\section{CONCULSION}

The minimal cost of implementing Wireless LAN will ensure that far more users will have wireless enabled laptops than previously envisaged.
Intel has already predicted that by the end of 2003 most of all new laptops will employ the new Banias chip and all new laptops will include wireless LAN. These figures may be high, but still anticipate a rapid growth of WiFi over the coming few months.

The Wireless LAN (WLAN) industry is also growing rapidly due to lower priced $\mathrm{WiFi}$ stations and a rapid standardization of the WiFi technology. Dual band protocols (3G and $\mathrm{WiFi}$ ) and development of the technology are expected to act as catalysts for growth in the wireless market for the years to come. WLAN services are beginning to appear to consumers in the form of WLAN services in coffee shops or other public premises and are becoming commonplace in applications such as trading floors, supermarkets, airports, hotels and are increasingly being used in office environments. Meanwhile the number of vendors keeps increasing, the technology keeps getting better and less expensive and with the recently completed IEEE 802.11 standard, interoperability between vendors is becoming less of an issue. Moreover, convenient form factors such as PC Cards are becoming common. It is easy to use and deploy WLANs and the cost is effective compared to wire LANs, which have many indirect and hidden costs associated with installation and reconfigurations.

There are many factors to be considered when deploying a wireless network. The proliferation of Access Point's has reached the point of requiring coordination and standardization to ensure full utilization of the technology. It's in the best interest of the enterprise to adopt a single IEEE 802.11 standard to ensure ubiquitous access for registered and authenticated wireless users. The single standard will also minimize overhead and expenditures that are normally associated with enterprises without technology standardization. 
Security requirements vary depending on the amount of network traffic and the level of secrecy required for the information being exchanged and the applications being used. While professional users typically require enterprise-quality security to allow secure conduct of confidential business, the security requirements of casual low-volume home users, using their network to print or share files, surf the Internet or exchange email with friends and family, tend to be less stringent. WiFi Protected Access is designed to meet these different requirements by running in two different modes - enterprise and home mode. The password kicks off the encryption process, which in WiFi Protected Access is called Temporal Key Integrity Protocol (TKIP). It then regularly changes and rotates the encryption keys so that the same encryption key is never used twice.

Finally as far as computers are concerned, the only form of total security is a computer locked in a room with no cables in or out. In all aspects of computing, security will always be an issue as hackers are usually one step ahead of the business world. Thus, as with everything, you have to balance security with how valuable you think the data is which you are protecting. The more security you use, the more expensive it is and the more inconvenience to your users. There are mainly different types of hackers that will try to hack your wireless network; all of them have one common goal such as the war drivers who are mainly just out for free Internet, or the more intelligent hacker who views your network as a potential target.

\section{REFERENCES}

1. Al-Alawi, A.I., 2005. Lecture notes, Available online from userspages.uob.edu.bh/aalalawi. Accessed 15 March 2005.

2. Slater, W.F.III, 2002. Internet History and Growth. Available from: http://www.isoc.org/internet/history/ Access on $3^{\text {rd }}$ April 2005.

3. Sherman, J., 2003. The History of the Internet. New York: Scholastic Library Pub.

6. Bahrain Telecommunication Company, 2005. BATELCO [online] Available from: http://www.bateclo.com.bh Accessed 20 Feb 2005.

7. Lewis, M., 2003. Living the WiFi High Life. MSNBC News. 16 Oct.

8. http:// www.mobilemag.com. Accessed 15 Jan 2005.

9. Levkowetz, H., 2004. Available online from: http://www.levkowetz.com/2003/voip/ieeinterview.html. Accesssed 25 Dec 2004.

10. Lyman, J., 2003. WiFi Security, Complexity and Future Debated. http://www.macnewsworld.com/story/32322.htm 1. Accessed 3 Feb 2005.

11. http://www.en.wikipedia.org/wiki/WiFi/advantages. Accessed 5 March 2005.

12. http://www.en.wikipedia.org/wiki/WiFi/disadvantages. Accessed 5 March 2005.

13. Bahrain Tribune, 2004. BATELCO launches WiFi service. Bahrain Tribune, April. http://www.menafn.com/qn_news_story_s.asp?S toryId=46243. Accessed 19 March 2005. 